\title{
Ice-shelf microtopography observed using satellite thermal imagery
}

\author{
P.S. ANDERSON \\ British Antarctic Survey, Natural Environment Research Council, Madingley Road, Cambridge CB3 OET, UK \\ E-mail: philip.s.anderson@bas.ac.uk
}

\begin{abstract}
Small anomalies in ice-shelf surface temperature correlate with measured microtopography. Clear-sky thermal infrared (TIR) images of the Brunt Ice Shelf, Antarctica, frequently show persistent patterns of anomalous snow surface temperatures. The anomalous signatures appear as stripes orientated along the ice flowline and are of the order of $5 \mathrm{~K}$ in magnitude. The positional persistence of the stripes suggests a topographic mechanism for their formation. In order to test this hypothesis, the TIR stripes are compared to a digital terrain model (DTM) derived from a kinematic global positioning system survey of the ice shelf. Ridges and valleys are seen in the DTM; the ridges correspond to the warmer TIR stripes, the valleys to the colder areas. In order to investigate the mechanism that couples elevation with thermal signature, two comparable but contrasting sets of clear-sky infrared images are presented, along with surface meteorological data. The first shows strong TIR stripes, whilst the second, despite similar snow- and air-temperature profiles, shows a weaker signature and smaller sensible-heat flux, $H$. Two possible mechanisms are presented which explain the TIR signature: surface elevation mapping onto the vertical air-temperature profile or, alternatively, enhanced surface sensible-heat flux on elevated areas. At present, there is insufficient information to resolve this uncertainty.
\end{abstract}

\section{INTRODUCTION}

Cloud-free thermal infrared (TIR) images of Antarctica during wintertime often show a wide range of features that result from the interaction of the continental topography with the large-scale and near-surface atmospheric temperature profile.

Higher ground generally appears cooler, as would be expected, but, in contrast, low-lying ice shelves are often significantly cooler than adjacent sloping terrain. Floating ice shelves have very small slopes, and the radiative cooling associated with wintertime clear-sky conditions allows the atmospheric surface layer to cool to many degrees below the overlying free atmosphere. On the Antarctic continent where slopes are steeper, such cooling is restricted by the onset of drainage flows which enhance mixing, and the variation of surface temperature with elevation more closely follows the dry adiabatic lapse rate (King and others, 1998).

Ice rises within ice shelves, with heights $>50 \mathrm{~m}$ relative to the surrounding ice shelf, show as persistent isolated warm features in these TIR images. The upper slopes of the ice rises extend above the shallow surface inversion overlying the ice shelf, and into air that is relatively warm and isothermal (King and others, 1998). Figure 1 shows a typical clear-sky TIR image of the Brunt Ice Shelf (BIS) where the $140 \mathrm{~m}$ high Lyddan Ice Rise is plainly visible.

The large temperature difference between wintertime iceshelf snow surface temperature (SST) and continental SST is occasionally perturbed by 'thermal plumes', streaks of warmer signature extending away from the grounding line and onto the ice shelf. Bromwich and others (1992) identify these as the remnants of continental katabatic flows, and describe such a plume extending across the Ross Ice Shelf. The thermal signature is formed by the enhanced wind speed of the katabatic outflow mixing the surface inversion over the ice shelf. Small-scale thermal plumes are visible in Figure 1 at the grounding line of the Stancomb-Wills ice stream.
Within the box area of Figure 1 are small ice-shelf thermal anomalies that initially appear similar to thermal plumes, but are more persistent, emerging on most occasions when the ice shelf is free of cloud cover during winter. Similar features have been noted on the Ross Ice Shelf by Casassa and others (1991) and are discussed in detail by Fahnestock and others (2000) where the signatures are assumed to be caused by topography. Casassa and others (1991) refer to these features as thermal stripes; they note that, when observed, their location appears to be fixed. The stripes observed on the BIS images have a similar persistence in location. The BIS stripes are of a different quality to the thermal plumes, having a constant length as measured by their extent from the grounding line.

The Methods section describes the approach taken to identify the mechanism that generates thermal stripes on ice shelves. The source of the TIR images is described along with the kinematic global positioning system (GPS) survey technique.

The Results section describes three TIR image sets. The first is used to correlate the thermal signature with a colocated digital elevation model derived from an in situ survey. The second and third TIR image sets are taken from 2003, when an enhanced set of micrometeorological and profiling equipment was in operation at Halley, situated on the BIS. The sets show time series of the TIR signature event from July 2003, and both exhibit little evolution over a period of 8 hours. Notable differences between the two TIR time series are examined and the corresponding micrometeorology data are presented which show the evolution of the lower atmosphere during the period of the case studies.

The first part of the Discussion section reviews the mechanisms that generate ice-shelf microtopography. The surface topography and thickness of grounded ice sheets depends on local accumulation and the underlying bedrock. The topography of a floating ice sheet, however, is dependent on the relative thickness of the ice sheet, which initially 


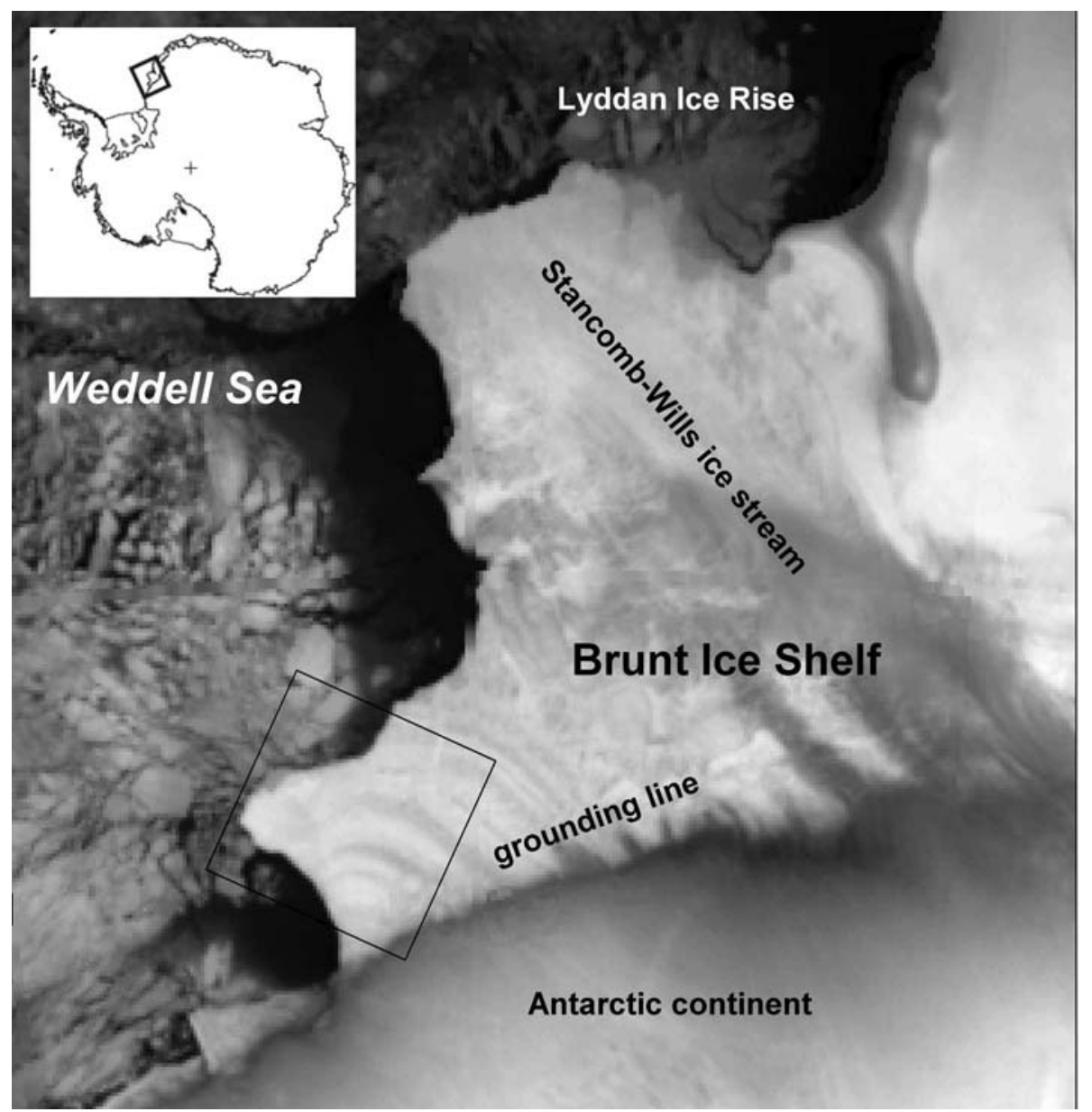

Fig. 1. AVHRR channel $4(10.3-11.3 \mu \mathrm{m})$ image of the BIS for 1915 UTC on 7 May 1999. Lighter shades are cold, darker shades warm. The cooler ice shelf is bordered by the warmer ocean and continental ice sheet, with the Lyddan Ice Rise also highlighted by surface temperature contrast. Katabatic thermal plumes flow onto the ice shelf along the Stancomb-Wills ice stream, whilst more subtle thermal signatures are apparent to the left, especially within the box area.

depends on the relative thickness of the ice sheet feeding the ice shelf. There is therefore a correspondence between iceshelf topography and the bedrock upstream of the grounding line. This correspondence leads to a correlation between the thermal signatures observed inland (due to katabatic flow) and that observed on the ice shelf, which I argue is due to iceshelf topography. For the BIS, this correspondence can lead to erroneous identification of ice-sheet topographic TIR signature as caused by the remnants of continental katabatic flow.

The second part of the discussion compares the possible mechanisms that link ice-shelf topography with TIR signature, based on the two time series of TIR images and their corresponding micrometeorology.

\section{METHODS}

In order to test whether the BIS image stripes were topographic in origin, the thermal image in Figure 1 was compared to a digital terrain model (DTM) derived from a purpose-made kinematic GPS survey of the area. Figure 2 shows the area chosen for the survey, and the resulting track of the overland traverse.

A suitable time series to observe the onset and development of the anomalous TIR signature has proved elusive. Such a time series requires a sequence of satellite passes over the area to coincide with the right meteorological conditions during a period when there are suitable supporting micrometeorological data. Although the onset has yet to be captured, two comparative series are presented showing near-stationary conditions. The mean strength of the TIR signature during the two case studies was extracted, presented as variance and extremes of the surface temperature within a defined area. In situ micrometeorological and surface energy-balance data associated with the TIR case study data are also presented.

\section{TIR imagery}

Advanced Very High Resolution Radiometer (AVHRR) channel 4 TIR imagery was obtained from the High Resolution Picture Transmission (HRPT) receiver at Rothera Research Station on the west-central part of the Antarctic Peninsula; the receiver and relevant post-processing are discussed in further detail in Turner and others (2001). The TIR images presented have been mapped onto a polar stereographic projection. Darker greyscales map to warmer temperatures. The images used here have had no correction applied to either emissivity or water-vapour absorption.

\section{Kinematic GPS survey}

Figure 2 shows the overland survey route taken to gather kinematic GPS data over the area where thermal stripes had been observed in the TIR images. The full survey was spread 


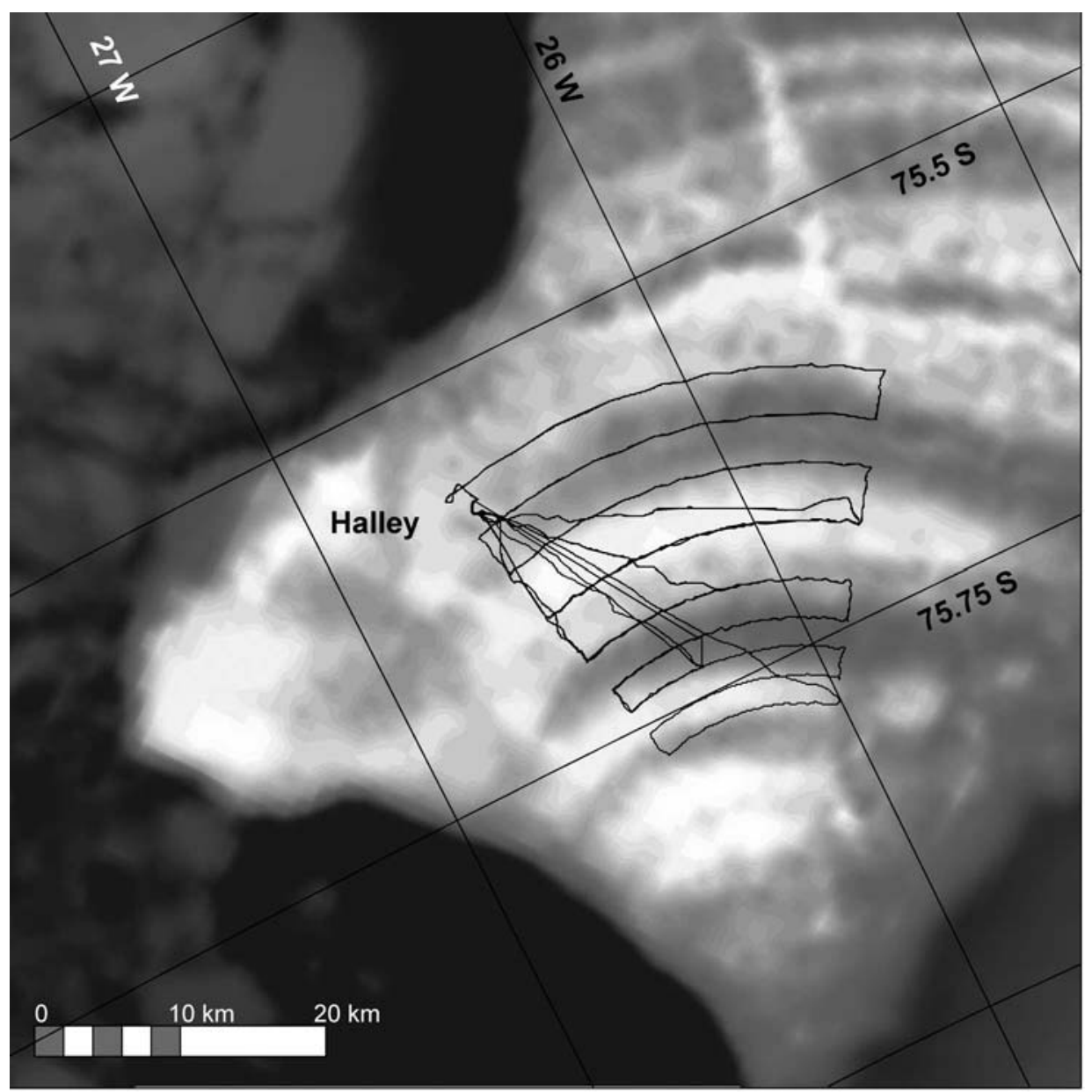

Fig. 2. Expanded view of the box area of Figure 1 with enhanced temperature contrast. The track of a ground-based kinematic survey is overlaid, correlating with warm bands observed in the thermal image. Halley station is at the confluence of the survey tracks.

over four separate days in May 2002, based from Halley station, so the location of common return indicates the position of Halley with respect to the thermal stripes. Curved survey arcs were chosen to coincide with the general path of the thermal stripes, with an arc separation of one-quarter separation of the stripes, i.e. $\sim 3 \mathrm{~km}$. The along-arc data were then averaged to a scale similar to the inter-arc distance, in order to smooth small-scale features experienced by the survey team and improve the elevation estimate.

A static kinematic unit remained on one of the science platforms at Halley, whilst a modified field skidoo carried the roving unit, comprising the GPS receiver, 100 Ah of external battery and the antenna mounted atop a short rigid mast. Kinematic GPS surveying relies upon an unbroken signal reception, so the receiving antenna needs to be above head height at all times. A standard hand-held GPS unit preprogrammed with suitable waypoints was mounted on the skidoo dashboard to enable the field party to navigate the required route without reference to the kinematic units. Each day of travel retracked the final survey arc from the previous trip in order to ensure accurate inter-arc elevations and eliminate tidal influences.

\section{Micrometeorology for 2003 data}

Micrometeorological data from the British Antarctic Survey's Halley station $\left(76^{\circ} 34^{\prime} \mathrm{S}, 26^{\circ} 36^{\prime} \mathrm{W}\right.$ in 2003) are available for winter 2003 as part of the Survey's ice-shelf boundary layer studies. Halley lies within the area selected for the TIR case studies. Standard aspirated air temperature and propeller/ vane winds were measured at 1, 2, 4, 8, 16 and $32 \mathrm{~m}$, with additional sonic anemometer turbulence probes at 4,16 and $32 \mathrm{~m}$. The $4 \mathrm{~m}$ sensible-heat flux, $H$, derived from eddy covariance analysis, is presented as part of the surface energy-balance data.

Snow and near-surface air-temperature measurements were made using a platinum resistance thermometers (PRTs) array with a $10 \mathrm{~cm}$ vertical resolution. The PRTs were clad in robust stainless-steel sheaths and mounted on a stout wooden dowel to maintain measurement spacing within the compacting snow. The steel and dowel were painted white to reduce insolation error within the snow. Although solar radiation was insignificant during the time of the case studies, the infrared behaviour of the white coating is unknown, and some suspicion must remain as to the accuracy of the above-surface PRT data presented. Under a net radiative cooling regime, as experienced during both case studies, the data may be cold-biased. I present the data with some level of confidence, as the surface PRT profiles agree in essence with the aspirated air temperatures.

Incoming and outgoing longwave radiation were measured using aspirated pyrgeometers, from Kipp and Zonen, type CG1. At $76^{\circ} \mathrm{S}$ at the times of these case studies, the sun is below the horizon, so shortwave radiation data are zero.

Snow heat flux, $G$, was estimated using the near-surface temperature gradient, $\mathrm{d} T_{\mathrm{s}} / \mathrm{d} z$, with an estimate of the snow thermal conductivity, $\lambda_{\text {snow }} \mathrm{d} T_{\mathrm{s}} / \mathrm{d} z$ was approximated by the 
Table 1. Variance $(\sigma T)$ and difference in extremes $(\Delta T)$ of the TIR signature within a selected area for the two case studies

\begin{tabular}{|c|c|c|c|c|}
\hline \multirow[t]{2}{*}{ Date } & Time & Mean $T$ & $\sigma T$ & $\Delta T$ \\
\hline & GMT & K & $\mathrm{K}$ & K \\
\hline 31 July 2003 (strong signature) & $\begin{array}{r}16: 35 \\
18: 15 \\
19: 55 \\
23: 15 \\
\text { Means and error }\end{array}$ & $\begin{array}{c}-42.6 \\
-42.3 \\
-40.9 \\
-40.3 \\
-41.53 \pm 1.10\end{array}$ & $\begin{array}{c}1.69 \\
1.71 \\
1.91 \\
1.42 \\
1.68 \pm 0.20\end{array}$ & $\begin{array}{c}7.06 \\
8.00 \\
8.94 \\
8.00 \\
8.00 \pm 0.77\end{array}$ \\
\hline 2 July 2003 (weak signature) & $\begin{array}{c}16.58 \\
18.38 \\
20.18 \\
23.38 \\
\text { Means and error }\end{array}$ & $\begin{array}{c}-45.4 \\
-47.9 \\
-48.8 \\
-47.7 \\
-47.45 \pm 1.45\end{array}$ & $\begin{array}{c}0.88 \\
0.82 \\
0.54 \\
0.78 \\
0.75 \pm 0.15\end{array}$ & $\begin{array}{c}4.47 \\
4.47 \\
3.92 \\
4.00 \\
4.21 \pm 0.30\end{array}$ \\
\hline
\end{tabular}

temperature difference from the uppermost pair of snow temperature sensors, that is:

$$
G=\lambda_{\text {snow }} \frac{\mathrm{d} T_{\mathrm{s}}}{\mathrm{d} z} \approx \lambda_{\text {snow }} \frac{T_{\mathrm{s}}-T_{\mathrm{b}}}{\Delta z},
$$

where $T_{\mathrm{s}}$ and $T_{\mathrm{b}}$ are adjacent snow PRTs, with $T_{\mathrm{s}}$ at or near the surface, and $T_{\mathrm{b}} 10 \mathrm{~cm}$ below. Hence $\Delta z=0.1 \mathrm{~m}$. Note that this convention has downwelling (away from surface) as positive. Direct measurements of $\lambda_{\text {snow }}$ were not available, but were estimated from

$$
\lambda_{\text {snow }}=\rho_{\text {snow }} C_{\text {ice }} \kappa_{\text {snow, }}
$$

where $\rho_{\text {snow }}$ is the snow density in $\mathrm{kg} \mathrm{m}^{-3}, C_{\text {ice }}$ is the known specific heat capacity of ice in $\mathrm{JK}^{-1} \mathrm{~kg}^{-1}$ and $\kappa_{\text {snow }}$ is the thermal diffusivity in $\mathrm{m}^{2} \mathrm{~s}^{-1}$. Measurements of snow density made at Halley during the 1995 austral winter gave $\rho_{\text {snow }}=$ $347 \pm 28 \mathrm{~kg} \mathrm{~m}^{-3}$ ( $8 \%$ variability). $\kappa_{\text {snow }}$ can be calculated from three points in a vertical snow temperature profile, assuming a constant diffusivity between the sensors:

$$
\kappa_{\text {snow }}=\frac{\frac{\mathrm{d} \theta}{\mathrm{d} t}}{\frac{\mathrm{d}^{2} \theta}{\mathrm{d} z^{2}}} \approx \frac{\frac{\Delta \theta}{\Delta t}}{\frac{\Delta\left(\frac{\Delta \theta}{\Delta z}\right)}{\Delta z}} .
$$

Using $0.1 \mathrm{~m}$ for sensor separation, and $600 \mathrm{~s}$ averaging period, the upper-level surface snow sensors gave $\kappa_{\text {snow }}=$ $4.3 \times 10^{-7} \mathrm{~m}^{2} \mathrm{~s}^{-1}$ for 31 July and $5.6 \times 10^{-7} \mathrm{~m}^{2} \mathrm{~s}^{-1}$ for 2 July, implying a mean value of $4.95 \times 10^{-7} \mathrm{~m}^{2} \mathrm{~s}^{-1}$ with a variability of $13 \%$. These data give $\lambda_{\text {snow }}=0.36 \pm 0.08 \mathrm{~m}^{2} \mathrm{~s}^{-1}$.

In general, the greatest snow temperature gradients occur near the surface, so these results are sensitive to the errors in temperature from the near-surface PRT as well as errors in the estimated snow surface level relative to the PRT array, that is, the thickness of the upper-level snow layer associated with the upper-level PRT.

Sensible-heat flux was measured by a Metek sonic anemometer mounted at $4 \mathrm{~m}$ above the surface, with the data corrected for tilt and flow distortion error using a planar fit to 3 months of winter data from 2003, according to Lee and others (2004). One-minute means of the $20 \mathrm{~Hz}$ data are presented.

\section{RESULTS}

\section{TIR imagery}

Figure 1 is a TIR image of the BIS for 7 May 1999. This event was chosen for the clarity of the anomalous thermal signature. The map inset shows the position of the image relative to the Antarctic continent, whilst the square indicates an area where the TIR anomaly is both most striking and most persistent. The whole image is free of cloud and exhibits a number of features typical of the area, including features that may be confused with the anomalous thermal signature under discussion. The boundaries of the Lyddan Ice Rise and continental ice slope show a sharp thermal contrast with respect to the ice shelf, but show a gradual cooling with altitude.

Large swaths of warmer signature are apparent, leading onto the ice shelf from the base of the Stancomb-Wills ice stream. A more subtle thermal signature is seen within the square, curving leftwards and decreasing in intensity towards the coast. It is these latter features that are the focus of the present discussion; they are similar in many ways to features noted on the Ross Ice Shelf by Casassa and others (1991) who refer to them as 'thermal stripes'. Both the BIS and Ross Ice Shelf stripes are locally persistent and vary somewhat in intensity, but when observed do not tend to vary in extent, unlike the thermal plumes which, although similarly fixed in location, vary in extent over hours or days. The persistence of the thermal stripes implies a topographic cause, although Casassa and others (1991) do not give conclusive evidence for this.

Figure 2 is the selected area of Figure 1 with increased contrast to highlight the thermal anomaly. Overlaid are latitude and longitude lines along with the route of a groundbased kinematic GPS survey designed to provide elevation data suitable for a simplified local area DTM.

Figures 3 and 4 are TIR images from 31 July 2003 converted into thermal contour maps. The TIR stripe signature is again visible, although not as apparent as for Figure 1. The images are the beginning and end of a sequence of five satellite passes, each passing over the BIS, four of the five over-flights having a coverage suitable for further analysis. The passes also coincide with surface meteorological measurements available from Halley during 2003. Figures 5 and 6 are from 2 July 2003, where the stripe signature is less well defined. A co-located sector from each image was selected to provide a quantitative assessment of the thermal mean and variance in each image; in addition to the TIR data presented, two interim satellite passes over the area are included in the variance analysis. The results of this analysis are given in Table 1 . The similarity of the images during 8 hours of TIR data coverage indicates that the SST field was quasi-stationary on each day. 

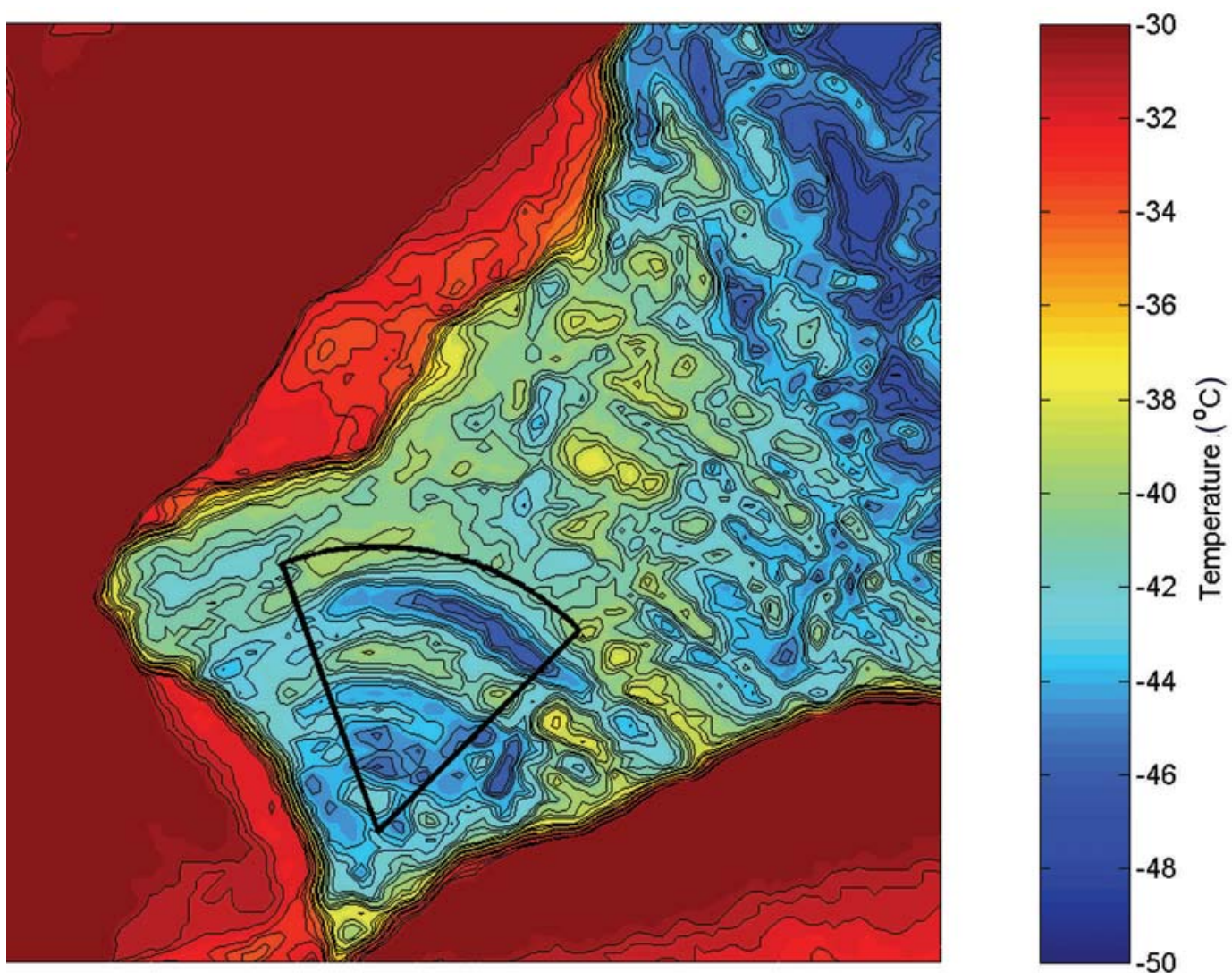

Fig. 3. AVHRR channel 4 image of a section of the BIS for 16:35 UTC on 31 July 2003, displayed as false-colour isotherm contours. The TIR signature is pronounced, static and stationary. Sectioned area indicates the data selected for temperature variance analysis.
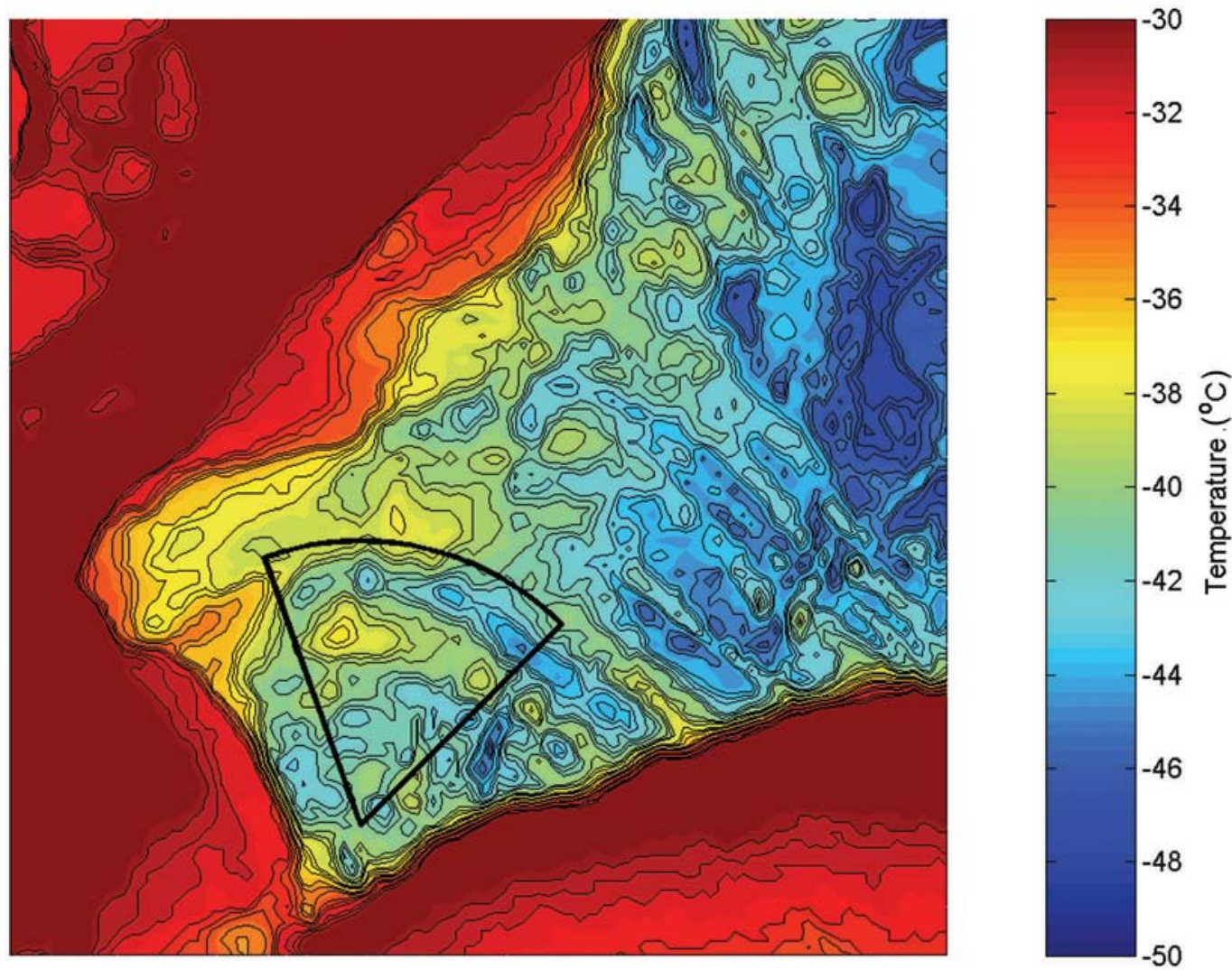

Fig. 4. Same as Figure 3, but for 23:15 UTC on 31 July 2003. 

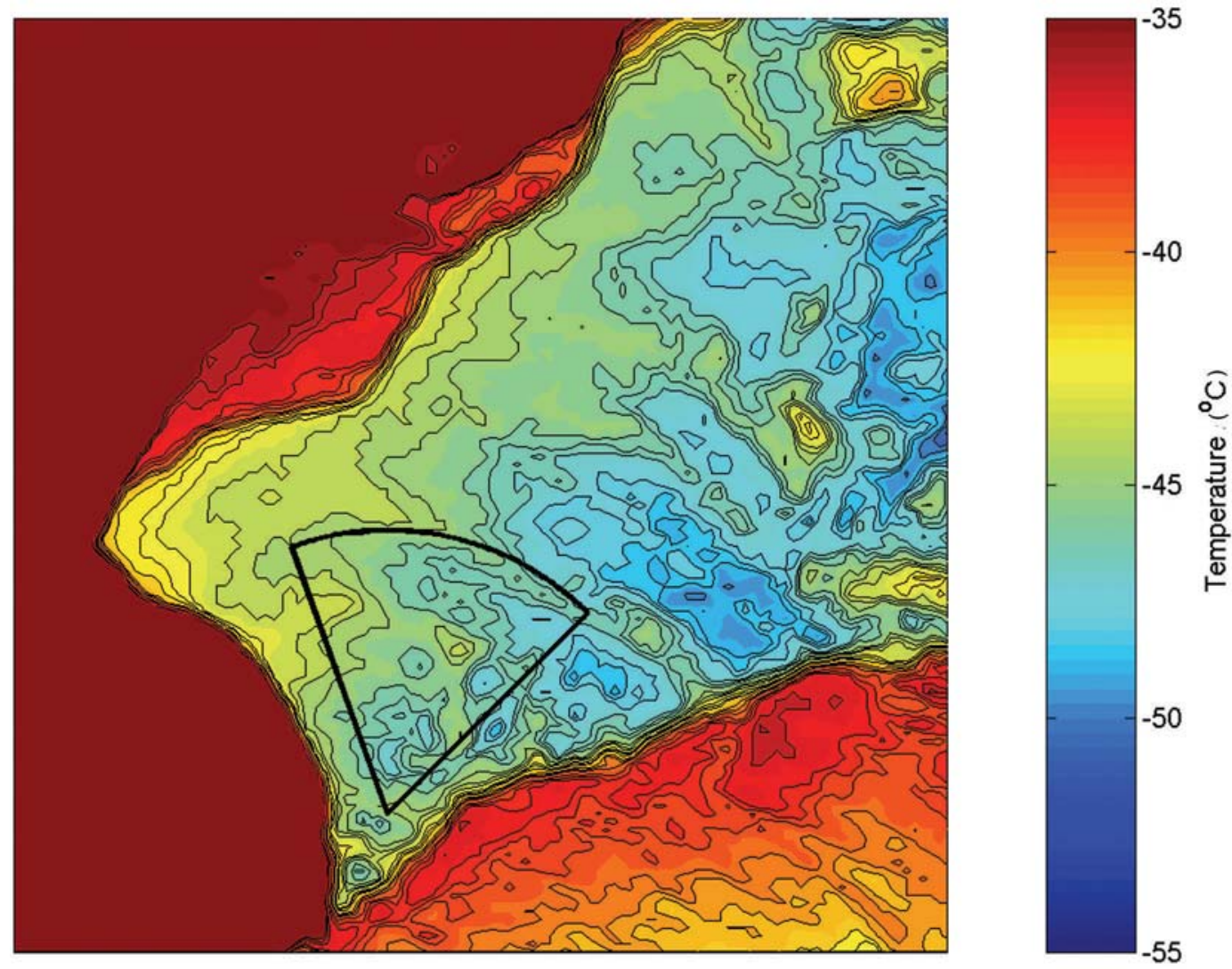

Fig. 5. AVHRR channel 4 image of a section of the BIS for 16:58 UTC on 2 July 2003, displayed as isotherm contours, with the same difference scaling as for Figures 3 and 4 . The TIR signature is clearly weaker than for 31 July.
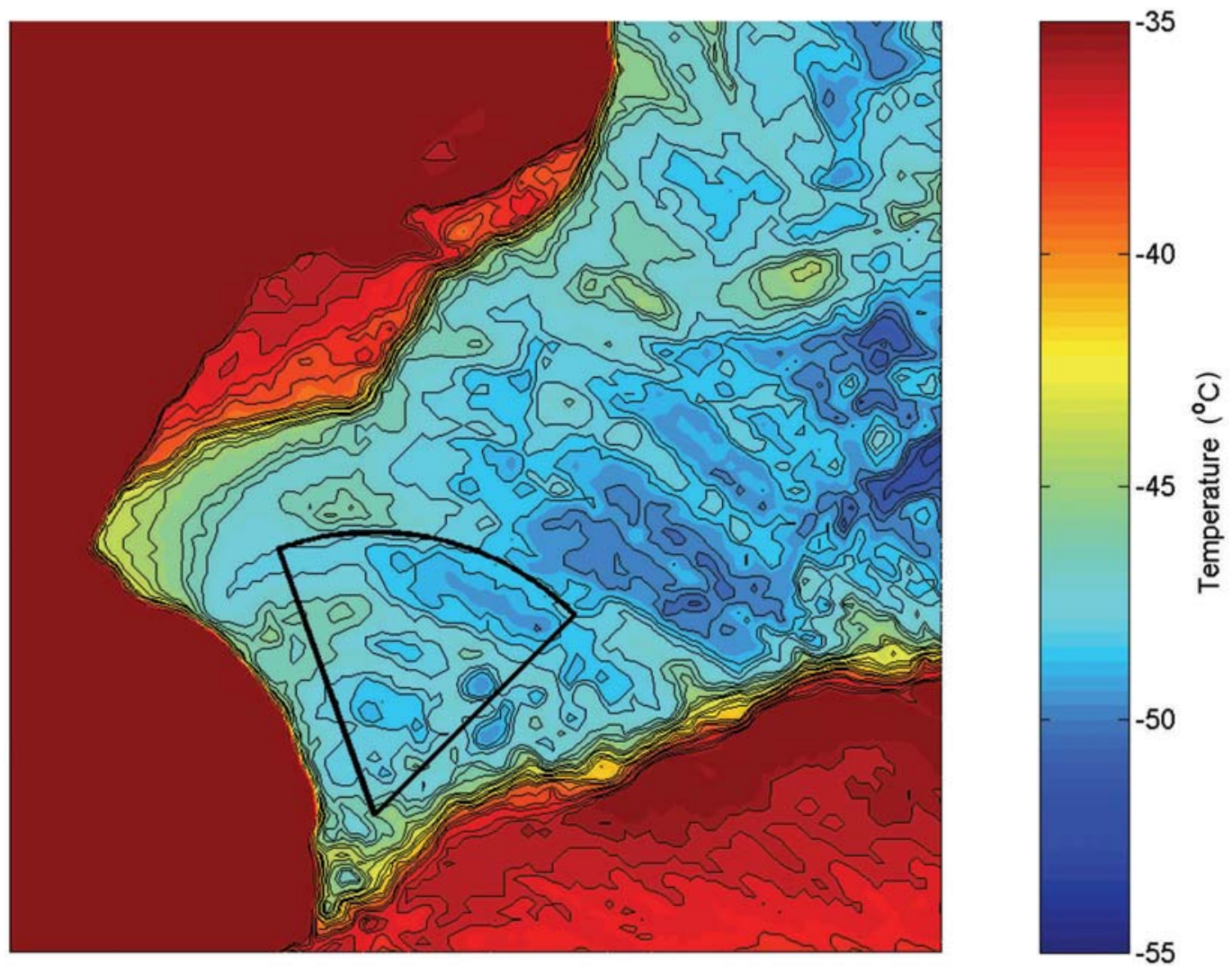

Fig. 6. Same as Figure 5, but for 23:38 UTC on 2 July 2003. 

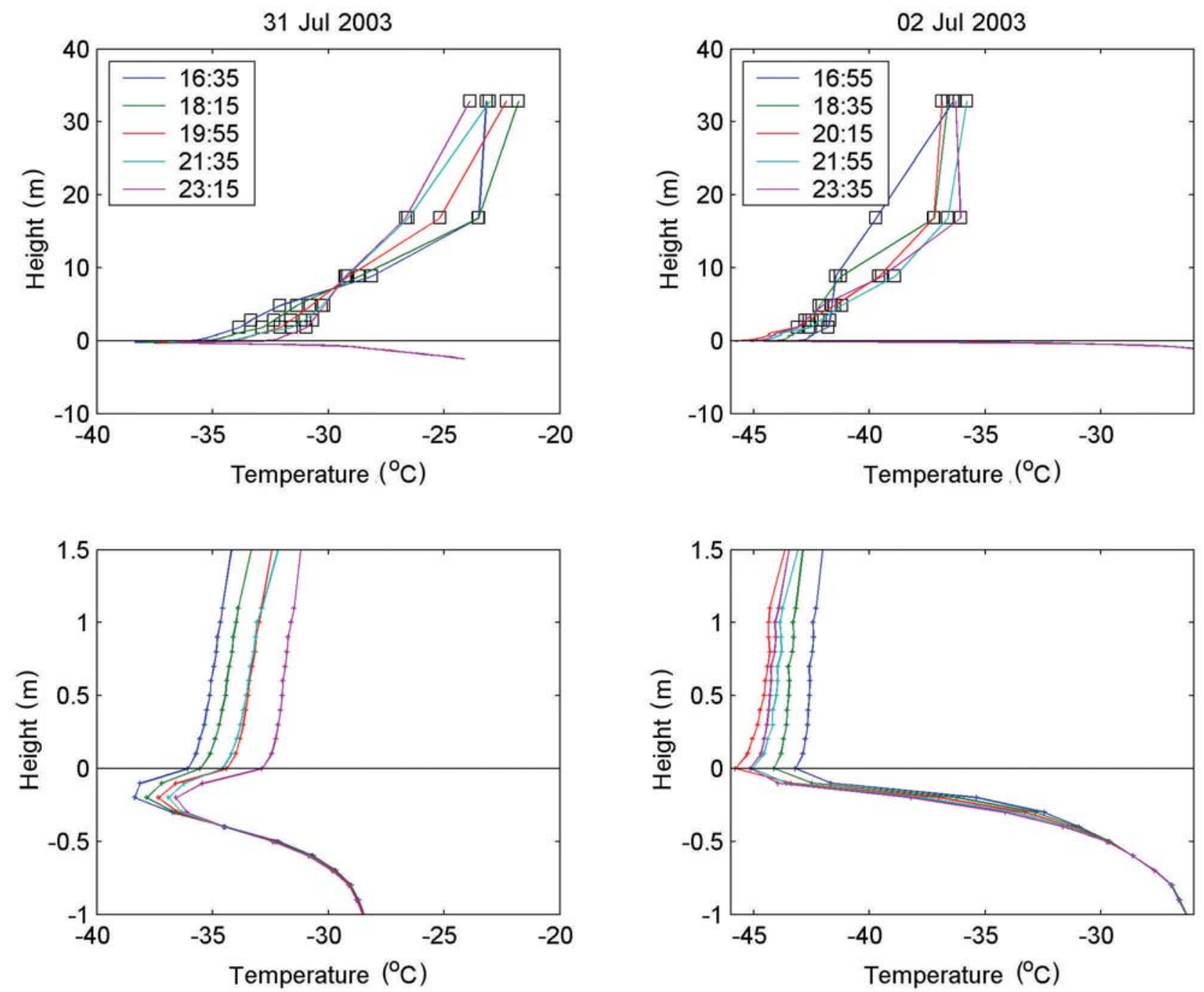

Fig. 7. Air- and snow-temperature profiles for 31 July 2003 (strong TIR signature) and 2 July 2003 (weak TIR signature). The profiles coincide with the times of AVHRR overpass used in the case study analysis, but also include the 18 hour passes for continuity, although the AVHRR data are unsuitable. The lower panels are expanded in the vertical to clarify the snow temperature structure. Squares indicate levels of aspirated air temperature; crosses indicate levels of 'snow' PRT sensors, with some exposed to the air. Note that the temperature axes on the two days have the same range but are offset.

\section{Meteorological data}

Figure 7 compares the air- and snow-temperature profiles for the two days, the lower panels being expanded in the vertical to show thermal structure in the near-surface snow. Figure 8 compares the snow heat flux, net radiation and wind speed. Details of the instrumentation are given in King and others (2001).

The air-snow temperature profiles in Figure 7 coincide with the times of the satellite passes used in the TIR timeseries analysis. Significant differences are apparent on the two days: during 31 July, when the TIR signature is strongest, near-surface atmosphere and SSTs increase with time, although the air above $8 \mathrm{~m}$ shows a cooling trend. In contrast, 2 July shows a cooling of the snowpack and nearsurface air, with a warming above the $8 \mathrm{~m}$ level.

Table 2 summarizes the temperature gradient information from the TIR images and the in situ mast data. (Height information for the TIR gradients has been extracted from the GPS survey: see below.) Both events coincide with a strong surface inversion at all times, but mean surface to $8 \mathrm{~m}$

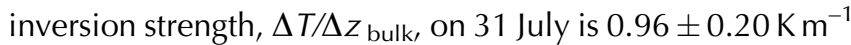
compared to $0.58 \pm 0.24 \mathrm{~K} \mathrm{~m}^{-1}$ on 2 July. Errors are one standard deviation.

$\Delta T / \Delta z_{\text {bulk }}$ is given by:

$$
\left.\frac{\Delta T}{\Delta z}\right|_{\text {bulk }}=\overline{T_{8}-T_{\mathrm{s}}} / 8.84
$$

$T_{8}$ is the $8.84 \mathrm{~m}$ aspirated air-temperature reading, and $T_{\mathrm{s}}$ is derived from the outgoing longwave radiation measurements, via:

$$
T_{\mathrm{s}}=\left(\frac{L_{\uparrow}}{\varepsilon \sigma}\right)^{0.25}-273 .
$$

$\sigma=5.67 \times 10^{-8} \mathrm{~W} \mathrm{~m}^{-2} \mathrm{~K}^{-4}$ is Stefan's constant and $\varepsilon$ is the infrared emissivity of snow. The uncertainty in the value of $\varepsilon$ for snow, 1-0.985 for typical infrared sensors, gives an uncertainty in surface net radiation, $R_{\mathrm{n}}$, for a given $T_{\mathrm{s}}$ of around $3 \mathrm{~W} \mathrm{~m}^{-2}$, or, conversely, an error in $T_{\mathrm{s}}$ for a given $L_{\tilde{a}}$ of $0.8 \mathrm{~K}$. These errors are small enough to ignore, and I have used $\varepsilon=1$. Table 2 also includes the surface to $32 \mathrm{~m}$ gradients, calculated in a similar fashion. 
31 Jul 2003
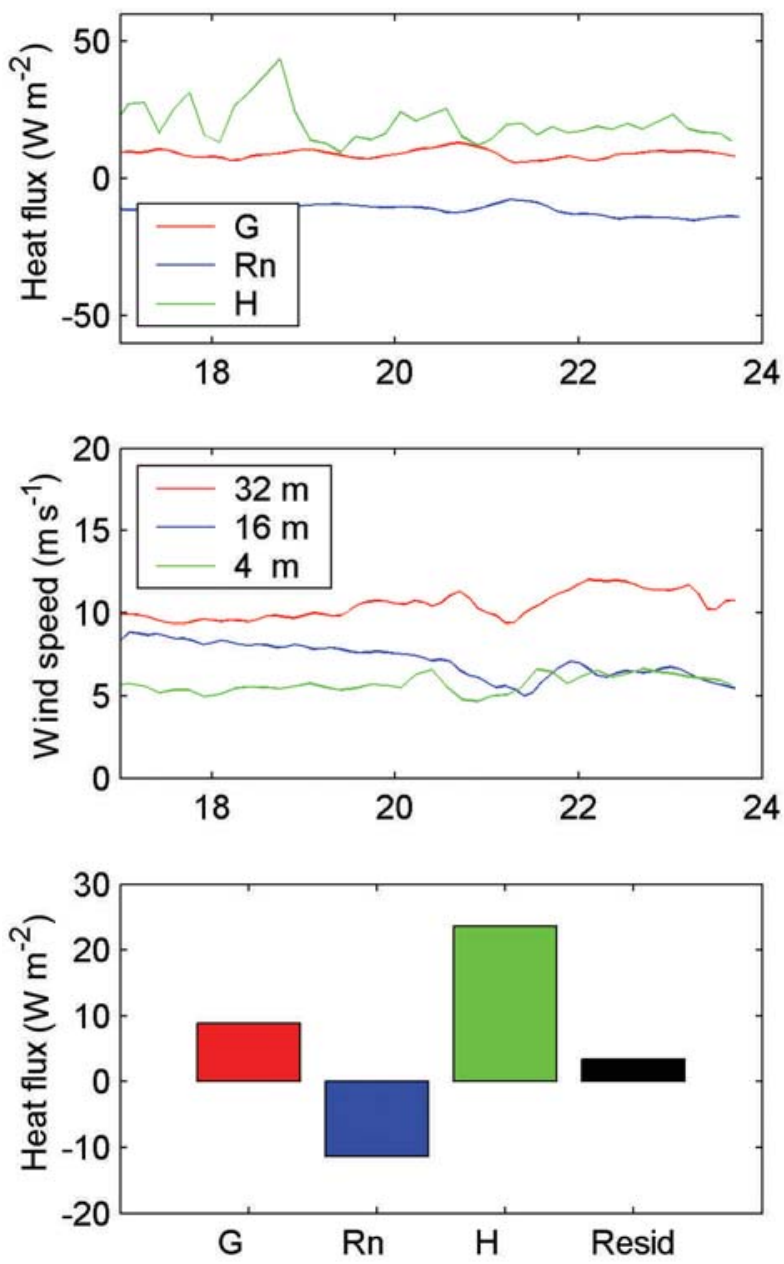

02 Jul 2003
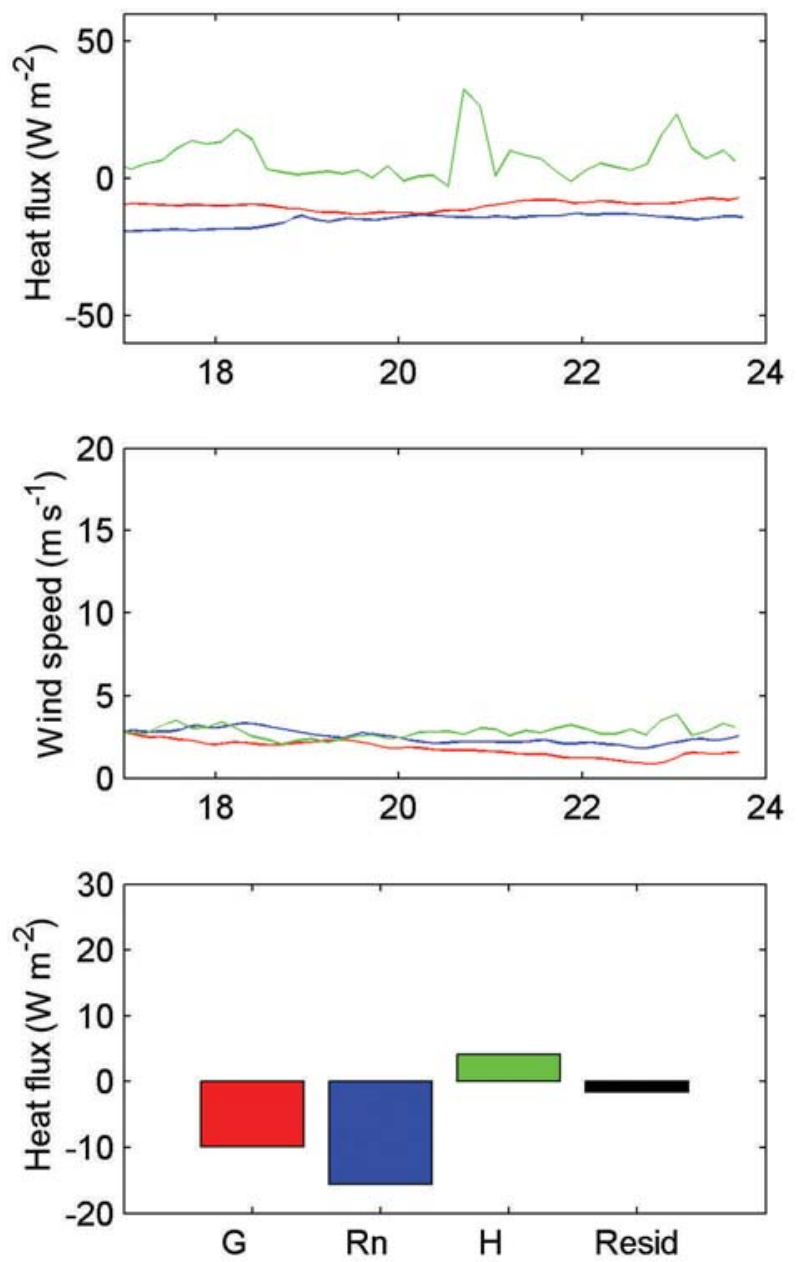

Fig. 8. Surface energy balance for 31 July 2003 (strong TIR signature) and 2 July 2003 (weak TIR signature). Upper panels show the time series during the period of the respective case studies, with the mean values summarized in the lower panels.

Figure 8 compares time series of the net radiation, snow surface and sensible-heat fluxes (upper panels), the wind speeds (middle panels) and the mean fluxes (lower panels) for the duration of the two TIR time series. The sign convention is that a downward flux is positive, i.e. at the surface:

$$
R_{\mathrm{n}}+H=G \text {. }
$$

Latent-heat transfer due to sublimation of the snow surface will be negligible for the clear-sky and low-wind events studied here (King and others, 1996) and is not included in the energy-balance analysis.
Table 3 collates the inversion strength data from Table 2 and summarizes the mean surface energy-balance data. The notable similarity between the two days is that the net radiation is acting to cool the surface, and is of roughly the same magnitude on both days. The snow heat flux, however, although of similar magnitude on both days, is opposite in sign, giving a flux into the snowpack on 31 July, but out of the snowpack on 2 July. The sensible-heat flux, $H$, is large on 31 July, and balances the cumulative effect of the radiation and snow heat flux. It is near zero on 2 July, as the snow heat flux is in balance with the radiation.

Table 2. Effective thermal gradients from the TIR data compared to two measures of surface inversion strength recorded co-temporally at Halley. The strong-signature event corresponds to a stronger inversion, and the two Halley gradients straddle the gradients derived from the TIR images

\begin{tabular}{|c|c|c|c|c|c|}
\hline \multirow[t]{3}{*}{ Date } & \multicolumn{3}{|c|}{ TIR- and GPS-derived gradients } & \multicolumn{2}{|c|}{ Inversion strength at Halley } \\
\hline & $\Delta T$ & $\Delta z$ & $\Delta T / \Delta z$ & $8 \mathrm{~m} \Delta T / \Delta z$ & $32 \mathrm{~m} \Delta T / \Delta z$ \\
\hline & K & $\mathrm{m}$ & $\mathrm{km}^{-1}$ & $\mathrm{~km}^{-1}$ & $\mathrm{~km}^{-1}$ \\
\hline 31 July 2003 (strong signature) & $8.61 \pm 0.29$ & 12.05 & $0.71 \pm 0.03$ & $0.96 \pm 0.20$ & $0.44 \pm 0.06$ \\
\hline 2 July 2003 (weak signature) & $5.44 \pm 1.17$ & 12.05 & $0.45 \pm 0.10$ & $0.58 \pm 0.24$ & $0.27 \pm 0.03$ \\
\hline
\end{tabular}


Table 3. Summary of the thermal gradient comparison, along with the surface energy-balance components and wind speeds for the two case studies. The TIR event with strong signature corresponds with larger local inversion strength and sensible-heat flux, as well as higher wind speeds

\begin{tabular}{|c|c|c|c|c|c|c|c|c|}
\hline \multirow[t]{3}{*}{ Date } & \multicolumn{3}{|c|}{ Temperature gradients, $\Delta T / \Delta z$} & \multicolumn{4}{|c|}{ Heat fluxes } & \multirow[t]{2}{*}{$u_{16}$} \\
\hline & TIR and GPS & $8 \mathrm{~m}$ & $32 \mathrm{~m}$ & $R_{\mathrm{n}}$ & $G$ & $H$ & Residual & \\
\hline & $\mathrm{km}^{-1}$ & $\mathrm{~km}^{-1}$ & $\mathrm{~km}^{-1}$ & $\mathrm{~W} \mathrm{~m}^{-2}$ & $\mathrm{~W} \mathrm{~m}^{-2}$ & $\mathrm{~W} \mathrm{~m}^{-2}$ & $\mathrm{~W} \mathrm{~m}^{-2}$ & $\mathrm{~ms}^{-1}$ \\
\hline 31 July 2003 (strong signature) & $0.71 \pm 0.03$ & $0.96 \pm 0.2$ & $0.44 \pm 0.06$ & -11.1 & 12.3 & 23.6 & -0.1 & $7.46 \pm 0.87$ \\
\hline 2 July 2003 (weak signature) & $0.45 \pm 0.10$ & $0.58 \pm 0.24$ & $0.27 \pm 0.03$ & -15.6 & -13.8 & 4.1 & 2.3 & $2.64 \pm 0.41$ \\
\hline
\end{tabular}

Taking the wind speed into consideration, the higher winds on 31 July will generate stronger surface-layer mixing than the winds on 2 July. Mixing within a stable surface layer will support the observed downwelling sensible-heat flux. The stronger air-temperature gradients measured on 31 July will further enhance $H$ compared to 2 July.

\section{Comparison of DTM and TIR thermal signature}

The curved tracks of the original GPS survey were used as guidelines to produce an orthogonal curvilinear grid with near-unity gridcell aspect ratio. The GPS data were then spline-interpolated onto this grid to generate a DTM, shown in Figure 9. The view is looking southeast and highlights the two ridges and valley region within the survey area. The mean ridge-to-valley-floor height difference is $10 \mathrm{~m}$, the maximum difference being $12.05 \mathrm{~m}$. The distance between the ridges is $\sim 14 \mathrm{~km}$. The altitude accuracy of the kinematic GPS survey technique is $3 \mathrm{~cm}$ (Vaughan, 1994), but this will be poorer for the DTM presented here due to the necessity of along-track smoothing and inter-track interpolation.

The horizontal positional data from the DTM were used to extract the corresponding SSTs from Figure 2. The TIR image in Figure 2 is from May 1999, and therefore 3 years older than the data used to generate the DTM. Although the ice shelf had spread to some extent between these dates, the local flow is approximately along the swaths of the survey. The clarity of the TIR signature from the May 1999 image ensures a large range of SST, and hence a strong signal with which to compare the DTM.

The resulting SSTs are draped as colour over the DTM and show a clear correspondence between the relative height of the surface and the SST. The point-by-point correlation coefficient between elevation and SST is $r^{2}=0.83$, i.e. a near-linear correlation between altitude and SST.

\section{DISCUSSION}

\section{Generation of microtopography on the Brunt Ice Shelf}

The existence of small-scale topographic flow features in ice shelves has been observed previously, predominantly on the Ross Ice Shelf, using thermal, visible and radar satellite imagery. Fahnestock and others (2000), in a study of flow features on the Ross Ice Shelf, list various terms for microtopographic features including 'flow traces' (Merry and Whillans, 1993), 'lineations' (Crabtree and Doake, 1980), 'flow bands' (Ferrigno and others, 1994), 'flow stripes' (Casassa and Turner, 1991) and 'foliation' (Hambrey and Dowdeswell, 1994).
The mechanism for the initial formation of flow stripes is not yet proven, although Casassa and Whillans (1994) suggest that their persistence within the ice shelf is due to a matching basal topography and a corresponding low transverse spreading rate. The BIS imagery, along with local knowledge of the ice flow near the grounding line, supports this view and suggests that the initial formation mechanism is due to the shape of the bedrock just upflow from the grounding line.

BIS TIR images show a correspondence between thermal stripes and occasional weak katabatic thermal signatures at the grounding line. Figure 1 shows a few examples of the effect, to the left of the more obvious thermal plume extending along the Stancomb-Wills ice stream. Both thermal stripes and the katabatic 'fingers' are persistent in position on the BIS. Both are sporadic in occurrence but, when seen together, originate at similar locations on the grounding line. Indeed, this correspondence confused the initial interpretation of the (topographic) BIS thermal stripes; the topographic signature was believed to be an extension of remnant katabatic flow. Katabatic flow on sloping terrain is enhanced by topography (Bromwich and others, 1992) as cool air drains into valley regions; confluence thus increases the flow rate. The ice-shelf katabatic fingers therefore imply the existence of valley regions (in the surface) immediately upflow of the grounding line. Depressions in the surface of ice sheets imply corresponding valleys in the underlying bedrock. In general, the ice surface depression is less marked than the bedrock depression, so the ice in this region is thicker than on a ridge. When the ice sheet from these thicker regions forms floating ice shelves, the thicker ice will stand proud due to buoyancy. The position of the katabatic fingers, at the grounding line of inland valley regions, happens to coincide with topographic thermal stripes.

\section{Mechanism for surface temperature/elevation correlation}

The terrain and thermal maps of the area covered by the kinematic survey show a strong correlation between iceshelf elevation and anomalies in SST, at least for the TIR image of 7 May 1999. Although the ice shelf has moved some distance between the capture of the TIR image and the GPS survey, the ice-shelf flowlines are virtually parallel to the thermal stripes, so the topography is relatively static (Thomas, 1973).

The initial interpretation for the thermal stripes is that elevation differences in the ice shelf are acting as a natural air-temperature profiler, i.e. the atmospheric temperature field over the ice shelf, $T_{\mathrm{A}}(x, y, z)$, evolves into an inversion 


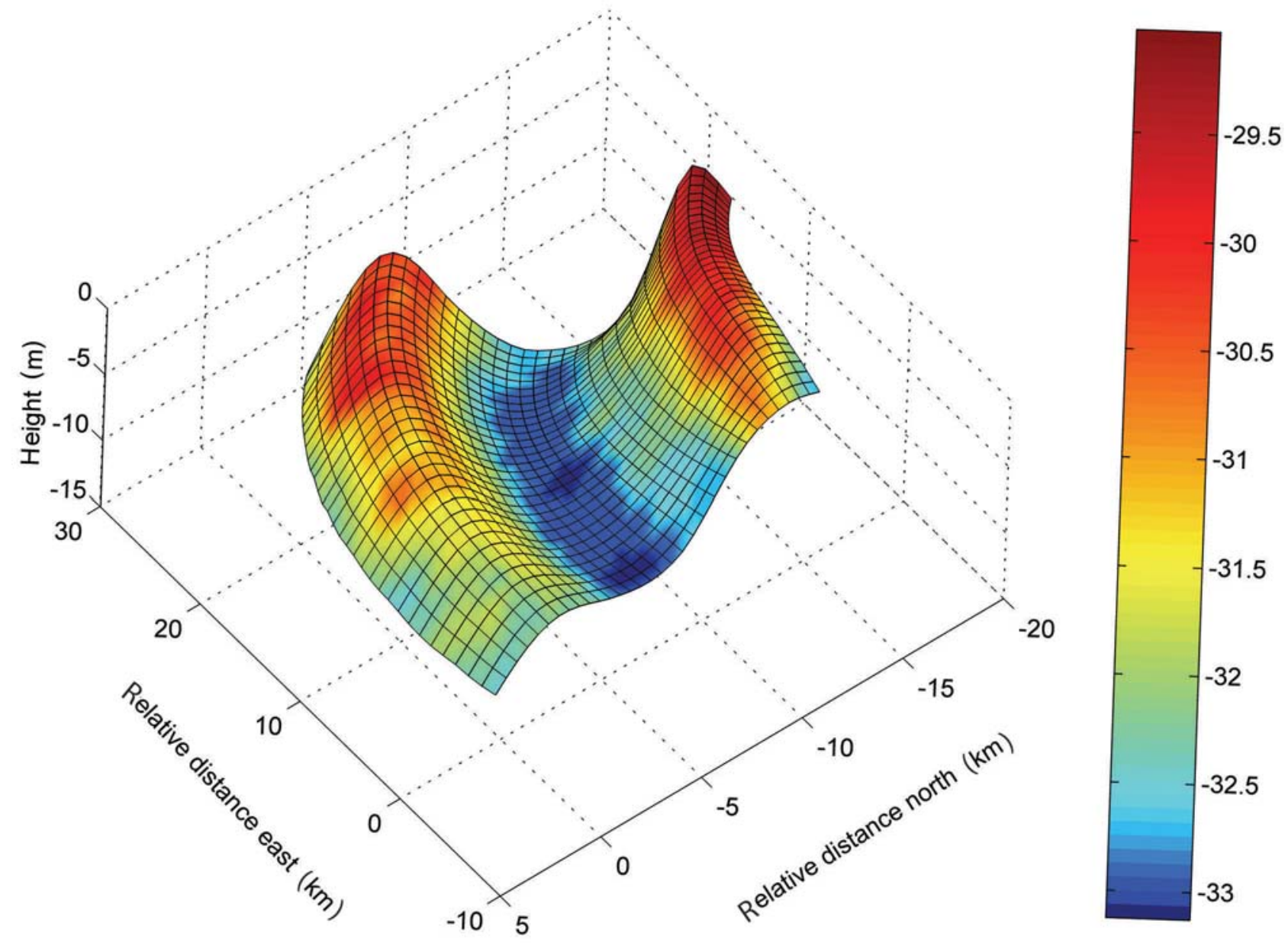

Fig. 9. DTM derived from the kinematic GPS survey with the corresponding TIR image temperatures from Figure 2 draped in colour, indicating the strong correlation $\left(r^{2}=0.83\right)$ between warm SST and higher elevation. The viewing direction is southwest.

with exactly horizontal isotherms, relative to mean sea level:

$$
\begin{aligned}
& \frac{\mathrm{d} T_{A}}{\mathrm{~d} x}=\frac{\mathrm{d} T_{A}}{\mathrm{~d} y}=0 \\
& \frac{\mathrm{d} T_{A}}{\mathrm{~d} z}=f(z) .
\end{aligned}
$$

Variations in the surface elevation, $\Delta h$, then intersect the airtemperature profile, $\mathrm{d} T_{\mathrm{a}} / \mathrm{d} z$, to give variations in SST, $\Delta T_{\mathrm{s}}$. Hence, expressed as gradients along a path, $\mathrm{l}$ :

$$
\frac{\mathrm{d} T_{\mathrm{s}}}{\mathrm{d} l}=\frac{\mathrm{d} T_{\mathrm{A}}}{\mathrm{d} z} \frac{\mathrm{d} h}{\mathrm{~d} l} .
$$

The case for TIR signature being generated by topography is supported by the comparison of the meteorology for the strong and weak TIR signature case studies. Table 1 presents the relevant data from the two case studies. The range in altitude from the kinematic GPS survey and the corresponding range in satellite-derived spatial temperatures over a similar area are compared to two measurements of inversion strengths at Halley. The thermal gradients at Halley straddle the gradient calculated from the TIR images and kinematic GPS heights. For both case studies, therefore, the temperatures in the valley regions are a linear extension of the inversion as measured at Halley, the station position being on the top of a 'ridge'. The mechanism that maintains such a linear profile and assumed horizontal atmospheric thermoclines may simply be pooling of cool air in the valley regions.
Alternatively, the warmer SST on the ridges could be due to sensible-heat flux, $H$, being enhanced in these regions. On cloud-free occasions we can expect the incoming longwave radiation to be similar over the whole ice shelf. Similarly, the absolute variation in SST is small, so the variability in outgoing longwave radiation is negligible. The $R_{\mathrm{n}}$ is virtually the same everywhere. Any change in $H$ will be matched by a change in SST. Sensible-heat flux is governed by the near-surface air-temperature gradients and the thermal diffusivity of the atmosphere, $\kappa$ :

$$
H=\rho c_{\mathrm{p}} \kappa \frac{\mathrm{d} \theta}{\mathrm{d} z},
$$

with $\rho$ the density of air and $c_{\mathrm{p}}$ the specific heat capacity of air at constant pressure. Note that downwelling $H$ is positive. $\kappa$ itself is proportional to the efficiency of the local mixing, which monotonically (but not linearly) increases with wind speed for a given atmospheric stability. The exact form of the relationship between $H$ and the gradients of wind and temperature is not well known for strongly stable conditions, but stronger winds for a given stable temperature-gradient regime would ensure a larger value of $H$ through the increase in $\kappa$.

The near-surface air-temperature gradients were strongest during the 31 July case study, but the wind speed was also higher, and the radiative cooling by $R_{\mathrm{n}}$ was almost balanced by $H$. Given that a ridge area is expected to have a higher 
wind speed than the areal mean, $H_{\text {ridge }}>H_{\text {valley, }}$ this provides an alternative, or additional, mechanism for topographic thermal signature. In reality, we may expect both a horizontally variable surface energy balance, and cooler valley regions due to the atmospheric temperature gradient. Drainage of cooled surface air down the valley slopes, and associated subsidence, will add to the complexity of the situation, and a complete analysis would depend on studies involving a suitable mesoscale model. A conceptual model is still worth discussing, however, if only to make further field and modelling studies ask the right questions.

\section{CONCLUSIONS}

Comparisons of TIR images of an ice shelf with an in situ topographic survey indicate a strong correlation $\left(r^{2}=0.83\right)$ between small changes in surface elevation $(<10 \mathrm{~m})$ and surface temperature. The positive correlation implies that warm flow stripes observed in TIR imagery of ice shelves elsewhere are lines of thicker ice shelf.

It is still not possible to be certain of the mechanism that governs the strength of the TIR signature. Two alternatives may be proposed, which are not mutually exclusive:

1. The surface is a passive indicator of the atmospheric temperature field. The atmosphere over the ice shelf will tend towards an equilibrium of horizontal thermoclines, and lower areas will be necessarily cooler. The strength of the signature for a given topography depends on the spatial mean near-surface air-temperature gradients.

2. The signature is derived from enhanced sensible heat flux on the higher elevations. Stratified airflow over modulating terrain will accelerate over ridges. Higher winds generate enhanced mixing through wind shear, magnifying heat flux towards the surface, and hence reducing or even reversing radiatively forced surface cooling.

To resolve this uncertainty, measurements of wind speed at two or more positions over the ice shelf are required, to check for any flow acceleration over the microtopography. At present, models of the strongly stable atmosphere are not sufficiently robust to clarify the issue with any confidence.

\section{ACKNOWLEDGEMENTS}

I thank S. Hinde and D. Cameron for making the kinematic GPS survey at Halley, C. Doake and J. King for assistance with the manuscript and valuable advice, and $\mathrm{H}$. Rott, C. Shuman and J. Cassano for reviewer comments.

\section{REFERENCES}

Bromwich, D.H., J.F. Carrasco and C.R. Stearns. 1992. Satellite observations of katabatic wind propagation for great distances across the Ross Ice Shelf. Mon. Weather Rev. 120, 1940-1949.

Casassa, G. and J. Turner. 1991. Dynamics of the Ross Ice Shelf. Eos, 72(44), 473, 481.

Casassa, G. and I.M. Whillans. 1994. Decay of surface topography on the Ross Ice Shelf, Antarctica. Ann. Glaciol., 20, 249-253.

Casassa, G., K.C. Jezek, J. Turner and I.M. Whillans. 1991. Relict flow stripes on the Ross Ice Shelf. Ann. Glaciol., 15, 132-138.

Crabtree, R.D. and C.S.M. Doake. 1980. Flow lines on Antarctic ice shelves. Polar Record, 20(124), 31-37.

Fahnestock, M.A., T.A. Scambos, R.A. Bindschadler and G. Kvaran. 2000. A millennium of variable ice flow recorded by the Ross Ice Shelf, Antarctica. J. Glaciol., 46(155), 652-664.

Ferrigno, J.G. and 7 others. 1994. Landsat TM image maps of the Shirase and Siple Coast ice streams, West Antarctica. Ann. Glaciol., 20, 407-412.

Hambrey, M.J. and J.A. Dowdeswell. 1994. Flow regime of the Lambert Glacier-Amery Ice Shelf system, Antarctica: structural evidence from Landsat imagery. Ann. Glaciol., 20, 401-406.

King, J.C., P.S. Anderson, M.C. Smith and S.D. Mobbs. 1996. The surface energy and mass balance at Halley, Antarctica during winter. J. Geophys. Res., 101(D14), 19,119-19,128.

King, J.C., M.J. Varley and T.A. Lachlan-Cope. 1998. Using satellite thermal infrared imagery to study boundary layer structure in an Antarctic katabatic wind region. Int. J. Remote Sensing, 19(17), 3335-3348.

King, J.C., P.S. Anderson and G.W. Mann. 2001. The seasonal cycle of sublimation at Halley, Antarctica. J. Glaciol., 47(156), 1-8.

Lee, X., J. Finnegan and K.T. Paw. 2004. Coordinate systems and flux bias error. In Lee, X., W. Massman and B. Law, eds. Handbook of micrometeorology. Dordrecht, etc., Kluwer Academic Publishers, 33-66.

Merry, C.J. and I.M. Whillans. 1993. Ice-flow features on Ice Stream B, Antarctica, revealed by SPOT HRV imagery. J. Glaciol., 39(133), 515-527.

Thomas, R.H. 1973. The dynamics of the Brunt Ice Shelf, Coats Land, Antarctica. Br. Antarct. Surv. Sci. Rep. 79.

Turner, J., G.J. Marshall and R. Ladkin. 2001. An operational, realtime cloud detection scheme for use in the Antarctic based on AVHRR data. Int. J. Remote Sensing, 22(15), 3027-3046.

Vaughan, D.G. 1994. Investigating tidal flexure on an ice shelf using kinematic GPS. Ann. Glaciol., 20, 372-376. 